\title{
Assessment of Knowledge on Biomedical Waste Management among Critical Care Health Workers in SMVMCH, Puducherry.
}

\author{
${ }^{*}$ Mr. Finny Moses E, **Dr. Danasu R
}

\begin{abstract}
:
Introduction: Nosocomial or Hospital-Associated Infections (HAI) is estimated to affect approximately $5 \%$ of hospitalized patients ${ }^{2}$. Objectives: 1 .To assess the knowledge among the critical care nurse regarding Bio-Medical Waste Management. 2.To determine the association between the knowledge of Bio-Medical Waste Management with their selected demographic variables. Methodology: Quantitative research approach with Descriptive research design was adopted to assess the knowledge regarding Bio-Medical Waste Management among critical care nurses. 100 Critical Care nurses were selected by simple random sampling techniqueat various private hospitals in Puducherry especially in areas of critical care unit. Result and conclusion: The knowledge regarding Biomedical Waste Management was satisfactory among Critical Care Nurses. Though working in critical care units, 19 (38\%) of the Critical Care Nurses lack adequate knowledge and 1(2\%) have poor knowledge regarding bio- medical waste management, which should be seriously considered in prevention of unwanted spreading of disease and resuming the eco-friendly environment. As these Critical Care Nurses are regularly engaged in the patient care in critical care units, they have the maximum opportunity in handling Biomedical Waste, therefore there is an urgent need for orientation training regarding the issue, to the staff nurses working in critical care units and entire health care personnel especially Para and non-medical workers to protect themselves including people visiting to hospital and nearby community.
\end{abstract}

Key words: Bio-Medical Waste Management, Infection Control, Hospital Waste Management.

\section{INTRODUCTION}

In recent years, there has been a growing awareness of the need for safe management of hospital waste for effective health service delivery. Nosocomial or Hospital-Associated Infections (HAI) is estimated to affect approximately $5 \%$ of hospitalized patients.[3] Hospitals are reservoirs for strains of bacteria that are multi drug resistant strains. There are however effective interventions for reducing the occurrence of HAIs. Studies have demonstrated that these infections are a reason of prolonged hospitalization and therefore increased costs adding to the patient's bill burden in a number of cases.[1]
Sharps waste, although produced in small quantities, is highly infectious. Poorly managed, they expose healthcare workers, waste handlers and the community to infections. [2] Contaminated needles and syringes represent a particular threat and may be scavenged from waste areas and dump sites and be reused. WHO has estimated that, in 2000, injections with contaminated syringes caused:

- 21 million hepatitis B virus (HBV) infections (32\% of all newinfections);

- Two million hepatitis C virus (HCV) infections (40\% of all new infections);

- 26oooo HIVinfections (5\% of allnewinfections). 
Epidemiological studies indicate that a person who experiences one needle-stick injury from a needle used on an infected source patient has risks of $30 \%, 1.8 \%$, and $0.3 \%$ respectively to become infected with $\mathrm{HBV}, \mathrm{HCV}$ and HIV. [9] In 2012, the results of a WHO assessment conducted in 22 developing countries showed that the proportion of healthcare facilities that do not use proper waste disposal methods ranges from $18 \%$ to $64 \%{ }^{[1]}$

Patients with hospital born infections have to pay higher bills for laboratory investigations and antibiotics and end up having a higher financial burden than those not affected.[4][5] Cost effective interventions such as regular hand washing, skin disinfections, use of gloves, fumigation of wards and OTs and an active microbiological surveillance system have proven to be effective in reducing these infections. ${ }^{[10]}$ Due to cost and time constraints these interventions are often overlooked. In addition hospital waste is highly infectious and toxic and their proper disposal is essential for prevention of cross infection to all. In India, the rate of generation of hospital waste is estimated to be 1.59 to 2.2 $\mathrm{kg} / \mathrm{day} /$ bed and out of which $10-15 \%$ is found to be bio-medicalwaste.

Inadequate waste management can cause environmental pollution, growth and multiplication of vectors like insects, rodents and worms and may lead to the transmission of diseases like typhoid, cholera, hepatitis and AIDS through injuries from syringes and needles contaminated with human. Some indicators like progressive increase in hospital infection rate, increasing resistance to wide variety of antibiotics are the pointers to the way in which poor hospital waste management can contribute to the ill health plaguing the health care institutions. ${ }^{[6][7] ~ I n ~ a d d i t i o n ~ t o ~}$ health risks associated with the poor management of bio-medical waste, due consideration must be given to the impact on environment, especially to the risks of pollution of water, air and soil. Hence, collection and disposal of waste in the proper manner is of great importance as it can decrease directly and indirectly health risk to people, and damage to flora, fauna and the environment. ${ }^{[8]}$

\section{OBJECTIVES OF THE STUDY:}

1. To assess the knowledge among the critical care nurse regarding Bio-Medical Waste Management.

2. To determine the association between the knowledge of Bio-Medical Waste Management and their selected demographic variables.

\section{METHODOLOGY:}

Quantitative research approach with Descriptive research design was adopted to assess the knowledge regarding Bio-Medical Waste Management among critical care nurse among 100 Critical Care nurses were selected by simple random sampling techniqueat various private hospitals in Puducherry especially in areas of critical care unit.

Development of data collection
instrument has two sections;
Demographic Data which comprises of
several demographic details of the
patients which is developed in the form of
direct questionnaires collected through
structured interview technique. Section II
- It consists of scoring sheet for multiple
questionnaires items of 30 objective type
questions. Total possible maximum score
for all items where 30.

Development of data collection instrument has two sections; Demographic Data which comprises of several demographic details of the patients which is developed in the form of direct questionnaires collected through structured interview technique. Section II - It consists of scoring sheet for multiple questionnaires items of 30 objective type for all items where 30 


\section{RESULTS \& CONCLUSION:}

Table 1: Frequency and percentage wise distribution

\begin{tabular}{|c|c|c|}
\hline LEVEL OF KNOWLEDGE & FREQUENCY & PERCENTAGE \\
\hline Adequate & 30 & $60 \%$ \\
\hline Moderate & 19 & $38 \%$ \\
\hline Inadequate & 1 & $2 \%$ \\
\hline
\end{tabular}

$\mathrm{N}=100$ 
3. Plianbangchang PH. W.H.O. Publication; "A Report on Alternative Treatment and Non-Burn Disposal Practices"; Safe Management of Bio-medical Sharps Waste in India.

4. Rao PH. Report: Hospital waste management--awareness and practices: A study of three states in India. Waste Manage Res. 2008;26:297-303. [PubMed]

5. Saini S, Nagarajan SS, Sarma RK. Knowledge; Attitude and Practices of BioMedical Waste Management Amongst Staff of a Tertiary Level Hospital in India. J AcadHosp Adm. 2005;17:2.

6. Shalini Sharma* and S.V.S.Chauhan, Assessment of bio-medical waste management in three apex Government hospitals of Agra, Journal of Environmental Biology, 29(2), p. p 159162 (2008)
7. Singh V. P., Biswas G., and Sharma, J.J., Biomedical Waste Management - An Emerging Concern in Indian Hospitals Indian, Journal of Forensic Medicine \& Toxicology, Vol. 1, No. 1. (2007-12).

8. Stein AD, Makarawo TP, Ahmad MF. A survey of doctors' and nurses' knowledge, attitudes and compliance with infection control guidelines in Birmingham teaching hospitals. J Hosp Infect. 2003;54:68-73. [PubMed]

9. Verma LK, Mani S, Sinha N, Rana S. Biomedical waste management in nursing homes and smaller hospitals in Delhi. Waste Manage Res. 2008;28:2723-34. [PubMed]

\section{SPINAL CORD INJURY}

(Paralysis Below The Level Of Injury)

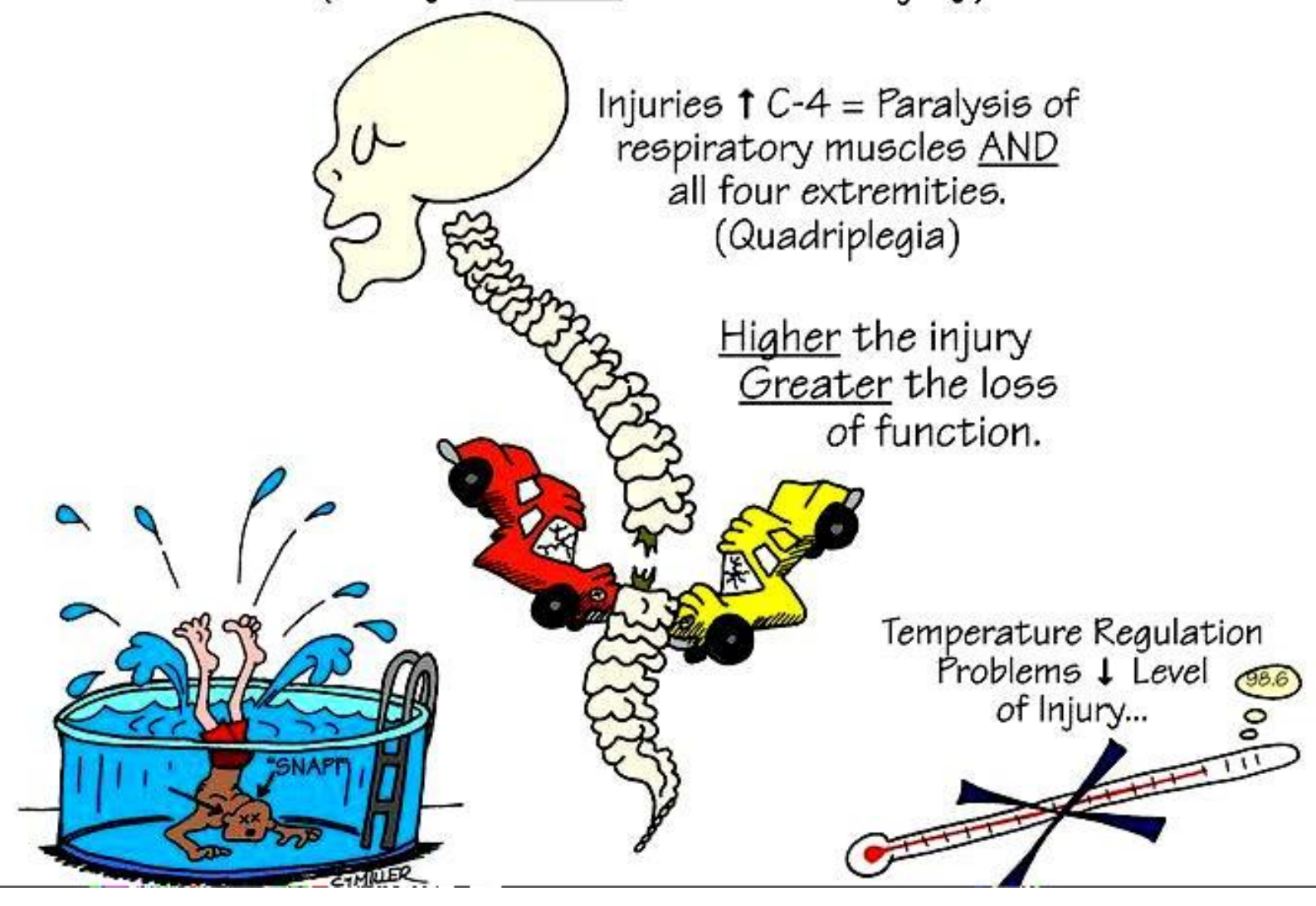

